\title{
Caput medusa: a sign of portal hypertension in case of chronic Budd-Chiari syndrome
}

\author{
Neelam Soni, ${ }^{1}$ Amrin Israrahmed, ${ }^{2}$ Priya Singh, ${ }^{2}$ Hira Lal (i) ${ }^{2}$
}

${ }^{1}$ Radiology, Sanjay Gandhi Post Graduate Institute of Medical Sciences, Lucknow, Uttar Pradesh, India

${ }^{2}$ Radiodiagnosis, Sanjay Gandhi Post Graduate Institute of Medical Sciences, Lucknow, Uttar Pradesh, India

Correspondence to Dr Hira Lal;

hiralal2007@yahoo.co.in

Accepted 13 April 2021

\section{DESCRIPTION}

Portal hypertension can occur due to several presinusoidal, sinusoidal and postsinusoidal causes leading to liver cirrhosis. Gilbert and Carnot initially coined the term 'portal hypertension' in 1902. ${ }^{1}$ The pathophysiology of portal hypertension in patients of liver cirrhosis is such that; initially there is distortion of blood vessels within the liver parenchyma due to hepatic fibrosis which results in an increase in portal pressure and clinically manifests as portal hypertension. In order to bypass this high pressure system, numerous low resistance vascular circuits become functional leading to portosystemic shunting of blood. ${ }^{1}$ At the umbilicus, blood from portal venous system is shunted through the umbilical and paraumbilical veins into the periumbilical systemic veins in the abdominal wall. The umbilical vein normally carries oxygenated blood from the mother to fetus in the antenatal period and closes within 1 week of birth. It gets recanalised in portal hypertension. ${ }^{23}$ Thus, portal hypertension clinically presents as multiple dilated, tortuous venous channels along the anterior abdominal wall and umbilicus giving rise to the 'caput medusa' appearance (figure 1A). The term 'Caput' is a Latin word for head. According to Greek mythology, 'medusa' was a monster with hair made of snakes, moving in all directions (figure 1B). The term 'caput medusa' is used for the appearance of distended and engorged umbilical veins, radiating across the umbilicus. Budd-Chiari syndrome is a type of hepatic venous

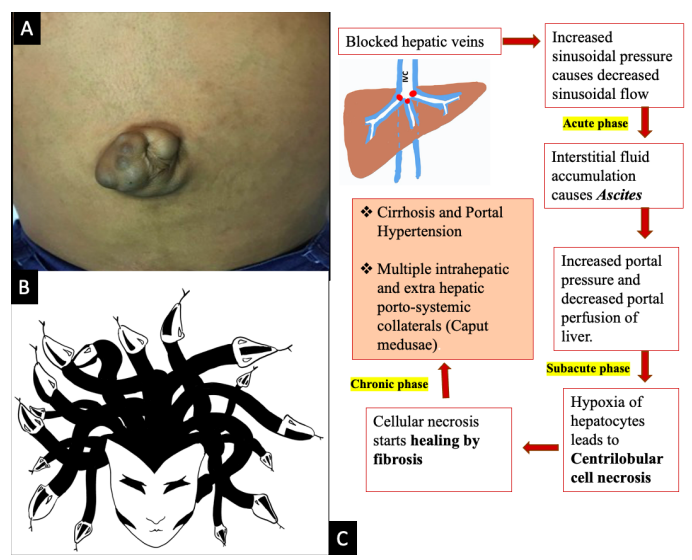

Figure 1 (A) Shows a patient with portal hypertension with tuft of vascular channels at umbilicus and prominent abdominal wall veins; (B) shows a diagrammatic representation of the Greek mythology character 'medusa' (original drawing by Amrin Israrahmed); (C) Schematic representation of pathophysiology of BuddChiari syndrome.

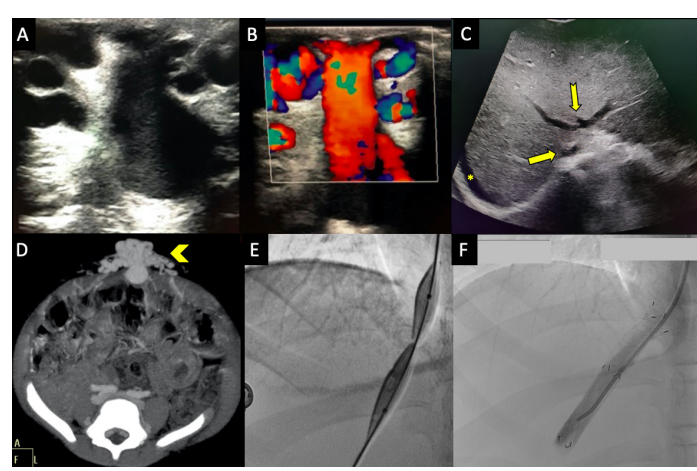

Figure 2 (A) Ultrasound image showing multiple tortuous and dilated network of vascular channels in the anterior abdominal wall near the umbilicus; $(B)$ Doppler image shows vascularity within the abdominal wall collaterals; (C) Ultrasound image shows the long segment ostial narrowing between the common ostium of the middle and left hepatic vein (yellow notched arrow) with the inferior vena cava (yellow arrow) along with perihepatic fluid (asterisk); (D) Contrast-enhanced CT abdomen in axial plane shows multiple dilated vascular channels protruding through the umbilicus; (E) Endovascular management of hepatic vein outlet obstruction with balloon angioplasty showing constriction at the stenotic site; (F) Poststenting venogram shows good intrastent flow.

outflow obstruction which results in an increase in the hepatic sinusoidal pressure causing liver congestion. Thus, it is an important cause of postsinusoidal type of portal hypertension (figure 1C). If the liver congestion (venous outflow obstruction) is not relieved immediately, then it further progresses from acute to chronic stages and results in hepatocyte necrosis and liver fibrosis further resulting in liver cirrhosis. ${ }^{4}$

We present a case of a 45-year-old man who presented with symptoms of vague abdominal pain and abdominal distension since the last 14 months. Abdominal examination revealed multiple tortuous veins on the abdominal wall giving the caput medusa appearance. Routine laboratory investigations revealed elevated alanine amino transferase $120 \mathrm{U} / \mathrm{L}$, aspartate transaminase $98 \mathrm{U} / \mathrm{L}$ and bilirubin $1.6 \mathrm{mg} / \mathrm{dL}$ with a decrease in platelet count of $80000 / \mu \mathrm{L}$ of blood. Ultrasound abdomen confirmed multiple venous collaterals in the subcutaneous plane of anterior abdominal wall near the umbilicus along with enlarged caudate lobe of liver and moderate ascites (figure 2A,B). Doppler showed a long segment block of the common channel of the middle and left hepatic veins and a short segment block of right hepatic vein near their ostium at the 


\section{Patient's perspective}

I am the patient. I was suffering from abdominal bloating sensation since more than 1 year. I noticed that several dilated linear channels were seen on my abdomen. I underwent routine blood check-up where my liver function tests were deranged. I was subsequently advised a doppler and ultrasound. I was detected with a disease called Budd-Chiari syndrome. I was quite shocked as I had never heard about this disease before. I don't consume alcohol, so I was wondering the cause of my disease. Doctors told me that it was an idiopathic disease. Subsequently in underwent CT scan and my disease was confirmed. I was given few medications, after which my abdominal bloating sensation has reduced a little bit but not completely. Doctors have advised that I will need to undergo stenting procedure. I managed to arrange the finances with some help from my extended family members. My procedure was performed wherein they have put a stent across my blocked vein in the liver. My bloating sensation has significantly reduced since then and the dilated veins of my abdomen have decreased in size. I feel much satisfied now. I am extremely humbled and thankful to my doctors for treating my disease and understanding my concerns. I hope to recover completely and plan to be regular on my follow-up.
Learning points

- Portal hypertension can occur due to various causesprehepatic, hepatic and posthepatic. Caput medusa is a clinical sign that helps in diagnosing portal hypertension.

- Chronic Budd-Chiari syndrome leads to liver cirrhosis and is an important cause of posthepatic type of portal hypertension.

- Chronic Budd-Chiari syndrome can be treated by various interventional radiological procedures and further liver damage can be prevented. Hence in endemic countries, if caput medusa is detected clinically then a routine abdominal doppler examination is essential to rule out this treatable aetiology causing liver cirrhosis.
Inferior Vena Cava (IVC), thus diagnostic of hepatic venous type of occlusion in Budd-Chiari syndrome (figure 2C). The IVC was normal in calibre. Contrast-enhanced CT abdomen was done for further evaluation, which showed multiple dilated vascular channels in the anterior abdominal wall draining into the periumbilical veins (figure 2D). Splenomegaly, mild ascites and long segment hepatic vein block was also confirmed on CT. The patient was subsequently put on anticoagulation and scheduled for hepatic vein angioplasty. Endovascular management was performed with balloon angioplasty and stenting of the right hepatic vein (figure 2E,F). A baseline Doppler study done 24 hours after the procedure revealed good flow within the stent with significant reduction in ascites and abdominal wall collaterals. The patient was discharged in stable condition with follow-up advised at 1, 3 and 6 months, respectively, in the first year postprocedure and annually thereafter.

Acknowledgements We would like to thank Dr Kasturi BK Rangan for helping us in obtaining the diagrammatic representation of the mythological creature Medusa. Also, we wish to thank Dr Shivanand $G$ for providing us with his valuable input in the figures section.

Contributors NS was primarily involved in data collection and drafted the final version of the manuscript. Al was involved in acquiring the images and drafting the figure legends. PS helped in data acquisition and $\mathrm{HL}$ was responsible for analysing and interpretation of the data. All the authors have participated sufficiently in the submission to take public responsibility for its content. The manuscript and its contents are approved by all authors.

Funding The authors have not declared a specific grant for this research from any funding agency in the public, commercial or not-for-profit sectors.

Competing interests None declared.

Patient consent for publication Obtained.

Provenance and peer review Not commissioned; externally peer reviewed.

\section{ORCID iD}

Hira Lal http://orcid.org/0000-0001-7957-635X

\section{REFERENCES}

1 Balducci G, Sterpetti AV, Ventura M. A short history of portal hypertension and of its management. J Gastroenterol Hepatol 2016;31:541-5.

2 Hari Kumar KVS, Rastogi SK. Caput medusae in alcoholic liver disease. Niger J Clin Pract 2011;14:508-9.

3 Singh NK, Cheema U, Khalil A. Caput medusae. Case Rep Child Meml Hosp Chic 2011;2010:bcr0320102795.

4 Cura M, Haskal Z, Lopera J. Diagnostic and interventional radiology for Budd-Chiari syndrome. Radiographics 2009;29:669-81.

Copyright 2021 BMJ Publishing Group. All rights reserved. For permission to reuse any of this content visit

https://www.bmj.com/company/products-services/rights-and-licensing/permissions/

BMJ Case Report Fellows may re-use this article for personal use and teaching without any further permission.

Become a Fellow of BMJ Case Reports today and you can:

- Submit as many cases as you like

- Enjoy fast sympathetic peer review and rapid publication of accepted articles

- Access all the published articles

- Re-use any of the published material for personal use and teaching without further permission

Customer Service

If you have any further queries about your subscription, please contact our customer services team on +44 (0) 2071111105 or via email at support@bmj.com.

Visit casereports.bmj.com for more articles like this and to become a Fellow 